\title{
Chloro(triphenylphosphole)gold(I) - A selective Chemosensor for Cysteine
}

\author{
MARUTHAI KUMARAVEL and MARAVANJI S BALAKRISHNA* \\ Phosphorus Laboratory, Department of Chemistry, Indian Institute of Technology Bombay, Powai, \\ Mumbai 400 076, India \\ e-mail: krishna@chem.iitb.ac.in; msb_krishna@iitb.ac.in
}

MS received 31 August 2015; revised 20 October 2015; accepted 11 November 2015

\begin{abstract}
Photophysical studies of luminescent gold complex of triphenylphosphole has been described. Addition of biologically relevant thio compounds was found to quench its fluorescence in methanol solution. Based on this, a simple and selective luminescence sensing method for cysteine detection has been developed.
\end{abstract}

Keywords. Phosphole; $\mathrm{Au}(\mathrm{I})$ complex; cysteine sensing; fluorescence quenching.

\section{Introduction}

Amino acids are the fundamental units of proteins and are essential for numerous processes, such as growth of new tissues, formation of histamine, adrenaline, insulin, urea and monitoring their level in the body. Cysteine, an essential $\alpha$-amino acid found in many natural proteins and physiological media, plays critical role in a variety of important cellular functions including detoxification and metabolism. ${ }^{1}$ Variation in the physiological level of thiols such as cysteine (Cys), homocysteine (Hcy), and glutathione (GSH) is linked to a number of diseases associated with leucocyteloss, psoriasis, liver damage, slow growth, hair depigmentation, edema, lethargy, liver damage, muscle and fat loss, skin lesions, weakness, cancer and AIDS. ${ }^{2}$ Considering these biological functions of cysteine, a constant awareness of its concentration is necessary.

Some trivial methods for cysteine quantification include capillary electrophoresis, ${ }^{3}$ high performance liquid chromatography, ${ }^{4}$ electrochemical analysis ${ }^{5}$ and mass spectrometry. ${ }^{6}$ Poor reproducibility, complicated sample preparation, requirement of expensive and sophisticated instrumentation are the demerits of these methods. In order to overcome these limitations, emphasis was given to utilizing optical methods based on thiol sensitive fluorophores. ${ }^{7}$ A number of luminescent transition metal-based chemosensors have been reported with excellent selectivity towards cysteine. ${ }^{8}$ Recently, several gold based colorimetric sensors (especially

*For correspondence gold nanoparticles) have been designed for cysteine detection due to their unique optical properties. ${ }^{9}$ Despite their usefulness, inorganic fluorescent nanoparticles still suffer from many drawbacks such as stability, photo-bleaching, cytotoxicity, poor tissue penetration of the excitation light, scattering light, and excessive tissue auto fluorescence under external illumination. ${ }^{7,10}$

Coordination of phosphine ligands stabilizes the oxidation state of gold against disproportionation to $\mathrm{Au}^{\mathrm{I}}$ and toxic $\mathrm{Au}^{\mathrm{III}}$ but facilitate exchange reactions with biological molecules. Phospholes are found to be more stable to air and moisture when compared to phosphines. As a part of our continuing interest in exploring new applications for organophosphorus compounds, ${ }^{11}$ herein we report the crystal structure and photophysical properties of $\mathrm{Au}^{\mathrm{I}}$ complex containing triphenylphosphole. The ability of the gold complex for selective detection of cysteine $\{$ hereafter Cys is demonstrated by fluorescence quenching experiments.

\section{Experimental}

\subsection{Materials}

The synthesis of ligand and the gold complex have been carried out according to previously reported procedures under a dry nitrogen atmosphere using standard Schlenk techniques. ${ }^{1,2}$ Solvents were dried and distilled prior to use by conventional methods. All amino acids were purchased from Aldrich and used without further purification. 


\subsection{Measurements}

The ${ }^{1} \mathrm{H},{ }^{31} \mathrm{P}$ NMR spectra were recorded in $\mathrm{CDCl}_{3}$ using a Bruker $400 \mathrm{MHz}$ instrument and tetramethylsilane $\left(\mathrm{Si}\left(\mathrm{CH}_{3}\right)_{4}\right)$ as the internal standard. Thermo gravimetric analysis is carried out with a Perkin Elmer Thermal Pyris system, under a stream of nitrogen gas at a heating rate of $10^{\circ} \mathrm{C} \mathrm{min}^{-1}$. Absorption and steady state fluorescence spectra were obtained with a Perkin-Elmer Lambda-35 and a PC1 photon counting spectrofluorometer manufactured by ISS, USA instruments, respectively. Quantum yields were determined using $2 \mu \mathrm{M}$ solutions in $1 \mathrm{~cm}$ cuvette, where the absorbance at the excitation wavelength $(366 \mathrm{~nm})$ is below 0.1 . The fluorescence quantum yields $\left(\Phi_{\mathrm{f}}\right)$ were estimated from the emission and absorption spectra by comparative method at the excitation wavelength of $366 \mathrm{~nm}$ using quinine sulphate $\left(\Phi_{\mathrm{f}}=0.542\right.$ in $\left.0.5 \mathrm{M} \mathrm{H}_{2} \mathrm{SO}_{4}\right)$ as standard. The following equation is used for the calculation of $\Phi_{\mathrm{f}}$ :

$$
\begin{aligned}
\Phi_{\mathrm{f}}= & \Phi_{\mathrm{f}}^{(\text {standard })} \times\left\{\left[\mathrm{F}^{(\text {sample })}\right]\left[\mathrm{A}^{(\text {standard })}\right] /\left[\mathrm{F}^{\text {(standard) }}\right]\right. \\
& \left.\times\left[\mathrm{A}^{\text {(sample) }}\right]\right\} \times\left\{\eta^{2 \text { (sample) }} / \eta^{2 \text { (standard }}\right\}
\end{aligned}
$$

where $\mathrm{F}^{\text {(sample) }}$ and $\mathrm{F}^{\text {(standard) }}$ are the integrated fluorescence intensities of the complex $[\mathbf{A u L}]$ and standard quinine sulphate, respectively. $\mathrm{A}^{\text {(sample) }}$ and $\mathrm{A}^{\text {(standard) }}$ are the absorbances of the $[\mathbf{A u L}]$ and quinine sulphate, respectively, at the excitation wavelength $366 \mathrm{~nm}$; $\eta^{\text {(sample) }}, \eta^{\text {(standard) }}$ are the refractive indexes of the media and $\Phi_{\mathrm{f}}^{\text {(standard) }}$ represents the quantum yield of the standard sample. All $\Phi_{\mathrm{f}}$ are corrected for changes in refractive index. Stock solutions of $2 \times 10^{-4} \mathrm{M}$ for the different amino acids were prepared in minimum amount of water $(0.5 \mathrm{~mL})$ followed by the addition of methanol $(9.5 \mathrm{~mL})$.

\section{Results and Discussion}

The gold(I) complex of triphenylphosphole \{hereafter, [AuL] \} has been synthesized in $98 \%$ yield and characterized by multinuclear NMR spectroscopic data. ${ }^{12}$ Since low-molecular weight species are deposited as thin films by vacuum evaporation for the fabrication of OLEDs, materials with good stability at higher operating temperatures are necessary. High decomposition temperature $\left(\mathrm{Td}_{10}\right.$ of $\left.267^{\circ} \mathrm{C}\right)$ which is a very important parameter for OLED materials, ${ }^{13}$ illustrates the higher thermal and morphological stability (Figure S5 and Table S1 in Supplementary Information). The complex $[\mathbf{A u L}]$ is stable towards air and moisture but is sensitive to light and decomposes gradually over a period of 3-4 days on exposure to visible light.

\subsection{Photophysical studies}

The absorption and emission spectra of [AuL] were recorded in methanol solution. The absorption wavelength $\left(\lambda_{\text {abs,max }}\right)$ for $[\mathbf{A u L}]$ is observed at $390 \mathrm{~nm}$ with molar absorption coefficient $\left(\log \varepsilon_{\max } / \mathrm{M}^{-1} \mathrm{~cm}^{-1}\right)$ of 4.67. These could be attributed to $\pi-\pi^{*}$ transitions of the conjugated system and with very less contribution coming from phosphorus substituents. The gold complex [AuL] showed good photostability and no decomposition was observed during the photophysical studies. The emission and excitation spectra for $[\mathbf{A u L}]$ are given in Figure 1, and the photophysical properties in different solvents are listed in Table 1. Gold atoms possess high absorption coefficient in the visible region, which ensures them to function as efficient quenchers for most fluorophores. As shown in Figure 1, the fluorescence intensity of $[\mathrm{AuL}]$ is red shifted and found to be ten-fold lesser when compared to phosphole. Complex [AuL] showed strong fluorescence emission at $\sim 490 \mathrm{~nm}$ upon excitation at $390 \mathrm{~nm}$. A perfect mirror image was obtained for the excitation and emission spectra of $[\mathbf{A u L}]$, indicating that both the absorbing and the emitting species are the same and no chemical modification was observed during the analysis.

On exposure to different excitation wavelengths, the same $\lambda_{\text {abs,max }}$ was observed. The observed emission bands were broad with full width at half maxima (FWHM) in the range of $96-108 \mathrm{~nm}$. The calculated Stokes shift for [AuL] observed in the range of $101 \mathrm{~nm}$ was greater than that observed in dibenzophospholes $(33 \mathrm{~nm}) .{ }^{13}$ Variation of solvents with different hydrogen donor ability induces negligible difference in the excitation and emission wavelengths. The quantum yield of

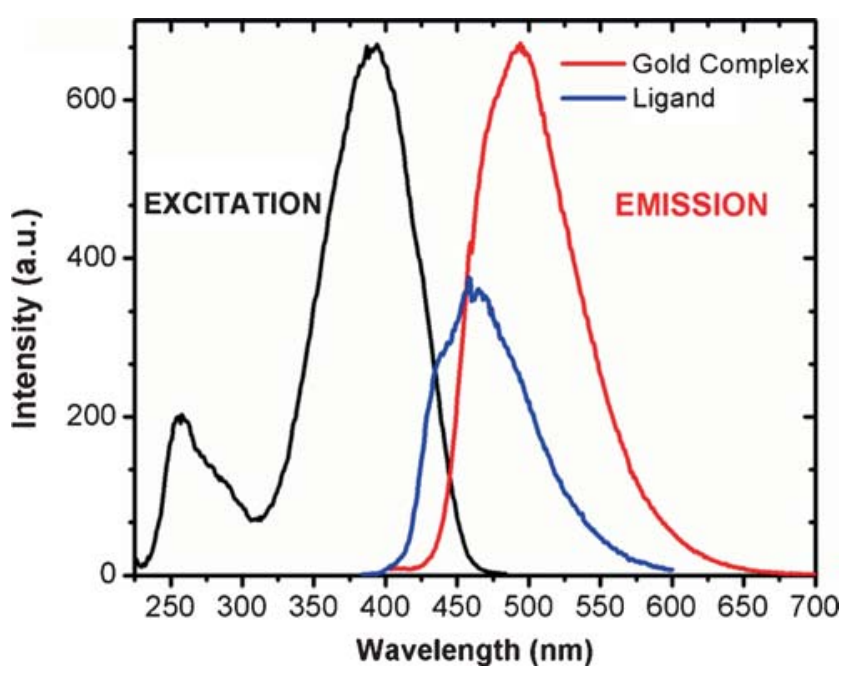

Figure 1. Excitation (black) and Fluorescence (red) spectra of $2 \mu \mathrm{M}$ of [AuL] in Methanol. 
Table 1. The photophysical data for compound [AuL] in different solvents.

\begin{tabular}{lcccccc}
\hline Solvent & $\lambda_{\text {abs }}(\mathrm{nm})$ & $\log \varepsilon_{\max }$ & $\begin{array}{c}\text { FWHM } \\
(\mathrm{em} ., \mathrm{nm})\end{array}$ & $\lambda_{\text {em }}(\mathrm{nm})$ & $\Delta v_{\text {st }}(\mathrm{nm})$ & $\Phi_{f}$ \\
\hline Toluene & 397 & 4.83 & 108 & 498 & 101 & 0.090 \\
$\mathrm{CHCl}_{3}$ & 396 & 4.45 & 104 & 498 & 102 & 0.079 \\
$\mathrm{THF}$ & 389 & 4.58 & 96 & 494 & 105 & 0.099 \\
$\mathrm{MeOH}$ & 390 & 4.67 & 103 & 491 & 101 & 0.064 \\
$\mathrm{CH}_{3} \mathrm{CN}$ & 391 & 4.49 & 99 & 492 & 101 & 0.048 \\
\hline
\end{tabular}

$\varepsilon_{\max }$ in $\mathrm{M}^{-1} \mathrm{~cm}^{-1}$

[AuL] measured in methanol is $6.4 \%$ which is comparable with the values reported for similar phospholes.

\subsection{Selective cysteine sensing using fluorescence}

Introduction of gold atoms results in orbital interactions which increase the energy level of lowest unoccupied molecular orbital (LUMO) and this property has been utilized frequently in the field of detection. ${ }^{14}$ To demonstrate the ability of [AuL] for detection of specific amino acids, solution phase detection studies were carried out by measuring its photoluminescence response in methanol towards successive addition of different amino acids. ${ }^{15}$ Preferential binding affinity towards various functional moieties present in natural amino acids would be the fundamental principle involved in fluorescence detection. Figure 2 demonstrates the fluorescence response of a $2 \mu \mathrm{M}$ solution of [AuL] towards $1 \mu \mathrm{M}$ solution of different amino acids. No change in the fluorescent intensity was observed for all amino acids except Cys. As shown, 44\% decrease in fluorescence intensity by Cys depicts that $[\mathbf{A u L}]$ is binding selectively towards thiol functional group. Further, the fluorescence titrations were carried out with different concentration of all 20 naturally occurring amino acids (figures 3 and S4 in SI). The unaltered fluorescence behavior of $[\mathbf{A u L}]$ in the presence of other amino acids is suggestive of the non-interactive nature of these amino acids with [AuL]. Figure 4 shows the fluorescence emission spectra of $[\mathbf{A u L}]$ in the presence of different concentrations of Cys. Fluorescence intensity of $[\mathbf{A u L}]$ decreases with successive addition of different concentration of cysteine. A good linear relationship between the decrease of fluorescence intensity and (a)

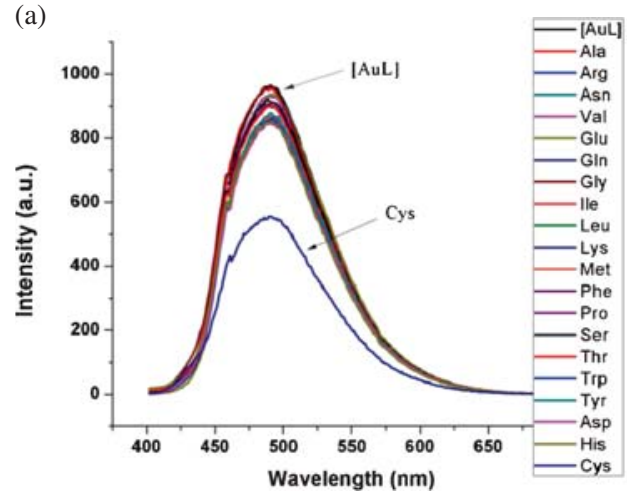

(b)

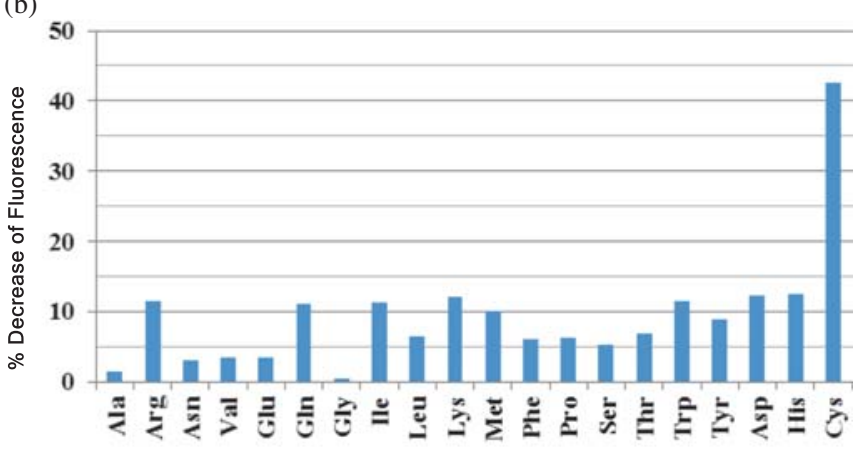

Figure 2. (a) Fluorescence spectra obtained for the titration of [AuL] with different amino acids in methanol, $\lambda_{\mathrm{ex}}=390 \mathrm{~nm}$. [AuL] $=2 \mu \mathrm{M}$. (b) Histogram showing the relative decrease in fluorescence intensity of $[\mathbf{A u L}](2 \mu \mathrm{M})$ in the presence of amino acids (aa's).

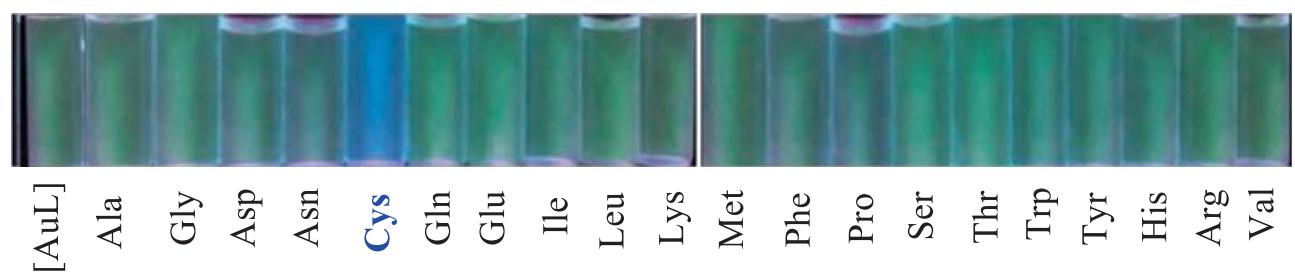

Figure 3. Visual fluorescent color change of [AuL] with different amino acids in methanol. 
amount of Cys added reflects the ability of [AuL] for quantitative measurement of concentration of Cys.

In order to understand the role of $-\mathrm{SH}$ group in selective sensing of Cys by [AuL], fluorescence titrations were carried out with other biologically relevant -SH containing molecules, viz., homocysteine (Hcy), and dithiothreitol (DTT (red) $_{\text {) }}$ (figures 5 and S4 in SI). In both the cases fluorescence of [AuL] has been quenched thus confirming the involvement of SH moiety. The other sulfur containing amino acid (methionine) did not quench the fluorescence which clearly indicates that $\mathrm{SH}$ group is essential and the sulphide group does not affect the fluorescence.

\subsection{Competitive titrations}

To check the selectivity of the recognition of [AuL] toward Cys, competitive amino acid titrations were carried out in the same medium with 19 other naturally occurring amino acids. The $\{[\mathbf{A u L}]+$ Cys $\}$ mixture which is in the quenched state when titrated with all other amino acids, resulted in very slight change in the fluorescence intensity (figure 6). This suggests that $[\mathbf{A u L}]$ is selective for only Cys owing to their unique $\mathrm{Au}^{+} \ldots \mathrm{SH}$ interaction. Differences in the intensity for Cys in solution phase was quantified using the Stern-Volmer equation: $\left(\mathrm{I}^{\circ} / \mathrm{I}\right)-1=K_{\mathrm{SV}}[\mathrm{A}]$. A linear Stern-Volmer relationship was observed for cysteine with high quenching constant of $3.6^{*} 10^{5} \mathrm{M}^{-1}$. Similarly, the quenching constants of Hcy and DTT are $2.9 * 10^{4}$ and $8.8 * 10^{5} \mathrm{M}^{-1}$, respectively. The plot is linear for a concentration of 0 to $1 \mu \mathrm{M}$ of Cys. For a concentration beyond $1 \mu \mathrm{M}$ of Cys, the Stern-Volmer plot becomes highly nonlinear. Thus, the detection limits are in the range of 0 to $1 \mu \mathrm{M}$ and if higher concentration of Cys is expected, the sample should be diluted appropriately. The minimum detection limit of Cys has been calculated using a $\sim 20$ arbitrary intensity unit difference between $[\mathbf{A u L}]$ and $[\mathbf{A u L}]$ upon addition of Cys. From this method, a minimum concentration of (a)

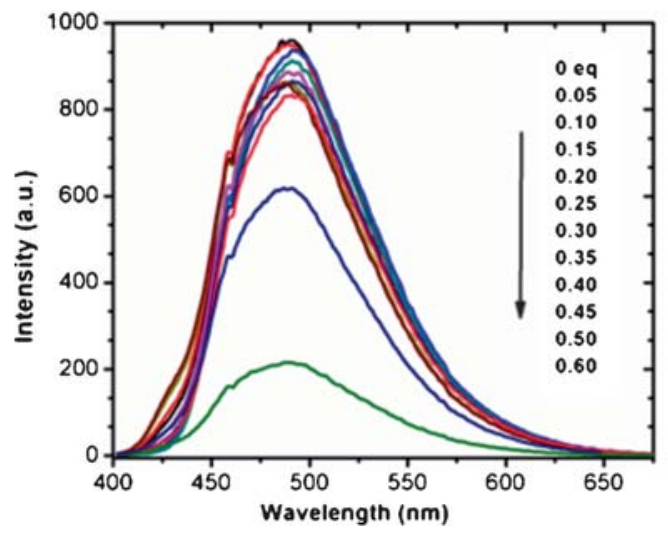

(b)

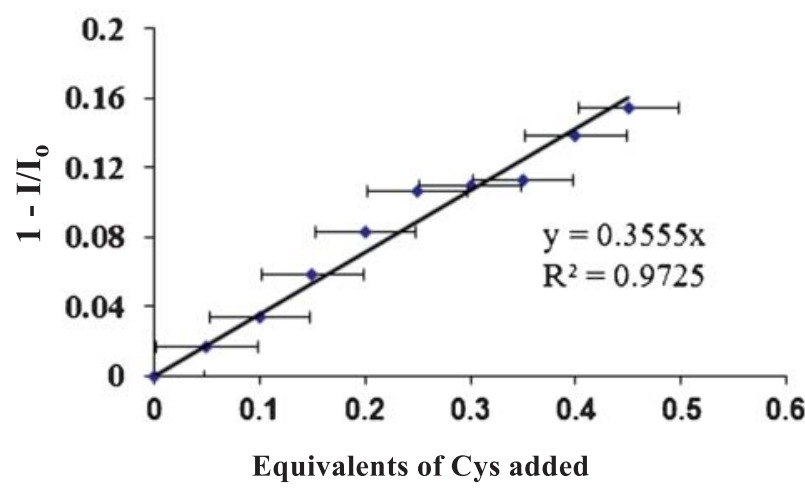

Figure 4. (a) Fluorescence spectra obtained during the titration of $[\mathbf{A u L}](2 \mu \mathrm{M})$ with Cys in methanol at $\lambda_{\mathrm{ex}}=390 \mathrm{~nm}$. (b) Stern-Volmer plot of fluorescence quenching of [AuL] with Cys with error bars.
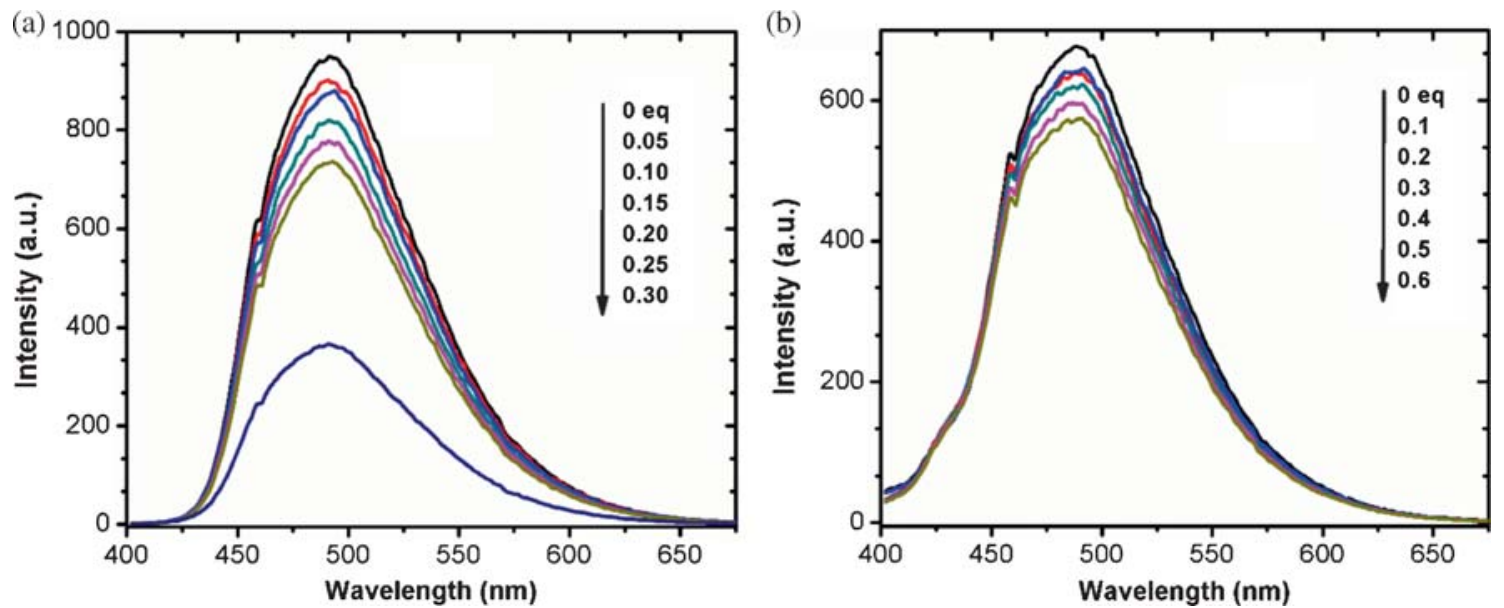

Figure 5. Fluorescence spectra obtained during the titration of [AuL] $(2 \mu \mathrm{M})$ with (a) DTT, (b) Hcy in methanol at $\lambda_{\text {ex }}=390 \mathrm{~nm}$ in methanol. 

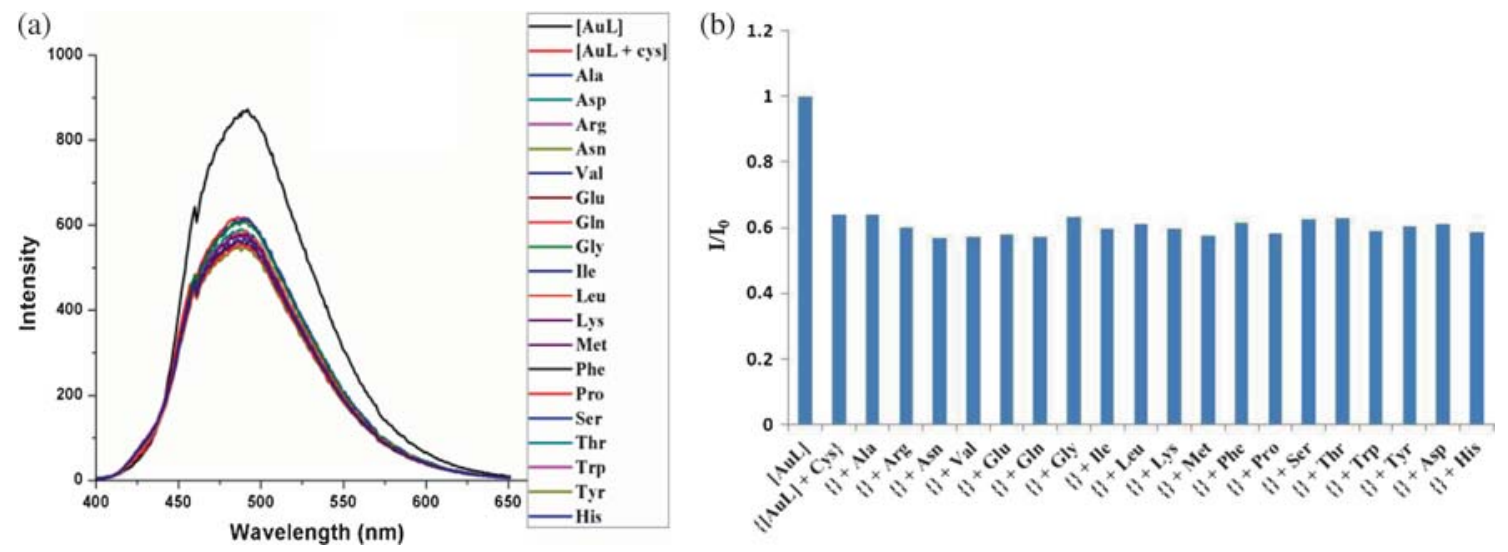

Figure 6. Competitive titration: (a) Fluorescence spectra obtained for the competitive titration of [AuL] $(2 \mu \mathrm{M})$ with Cys $(1 \mu \mathrm{M})$ in the presence of different aa's; (b) Histogram showing the fluorescence response of $[\mathbf{A u L}]$ in presence of Cys followed by different amino acids $\left(\lambda_{\mathrm{ex}}=390 \mathrm{~nm}\right)$ in methanol. [AuL] $=2 \mu \mathrm{M}$; $[\mathrm{AA}]=2 \mu \mathrm{M}$.

$0.5 \mu \mathrm{M}$ solution of Cys can be detected. The lower limit of detection is $500 \mathrm{nM}$ through this method but other complexes exhibit much lower detection in the range of $0.02-1 \mathrm{nM}$. This fluorimetry method using [AuL] for cysteine sensing has moderate activity when compared with other methods of detection (Table S2 in SI). The absorbance spectrum of [AuL] did not deviate much in the presence of Cys. The mechanism of quenching of fluorescence can be attributed to either simple coordination to gold(I) ions thereby making a tri-or tetra-coordinated complex or through the replacement of $\mathrm{Au}-\mathrm{Cl}$ bond with $\mathrm{Au}-\mathrm{SR}$ retaining the linear geometry. ${ }^{16}$ Isolation of certain thiolate complexes of gold(I) phosphole supports the latter mechanism. ${ }^{17}$

\section{Conclusions}

The interaction of gold(I) phospholyl compound with various amino acids has been studied. Since, thiol containing cysteine has unique binding properties among the twenty amino acids, it brings about a distinctive response to the fluorescence of gold(I) complex of triphenylphosphole. Similar biologically important thiols like DTT $_{\text {red }}$ and Hcy also exhibit quenching properties thereby enabling their detection.

\section{Supplementary Information}

${ }^{31} \mathrm{P}$ NMR spectrum, emission spectra at different wavelengths and TGA profile of $[\mathbf{A u L}]$ are included in the supporting information. Fluorescence spectra obtained for the titration of [AuL] with all 19 amino acids in methanol and DTT and Hcy along with their Stern-Volmer plots are also provided. The electronic supplementary information is available at www.ias.ac.in/chemsci.

\section{Acknowledgements}

We are grateful to the Science \& Engineering Research Board, New Delhi, India, for financial support of this work through grant No.SB/S1/IC-08/2014. MK thanks the Council of Scientific Industrial Research (CSIR), New Delhi, for Senior Research Fellowship (SRF).

\section{References}

1. (a) Refsum H, Ueland P M, Nygård $\mathrm{O}$ and Vollset $\mathrm{S} E$ 1998 Annu. Rev. Med. 49 31; (b) Paulsen C E and Carroll K S 2013 Chem. Rev. 1134633

2. (a) Kleinman W A and Richie Jr J P 2000 Biochem. Pharmacol. 60 19; (b) Staal F J T, Ela S W, Roederer M, Anderson M T, Herzenberg L A and Herzenberg L A 1992 Lancet 339909

3. Raoof J-B, Ojani R and Baghayeri M 2009 Sens. Actuators B: Chem. 143261

4. Amarnath K, Amarnath V, Amarnath K, Valentine H L and Valentine W M 2003 Talanta 601229

5. Xu H, Xiao J, Liu B, Griveau S and Bedioui F 2015 Biosens. Bioelectron. 66438

6. Tsikas D, Raida M, Sandmann J, Rossa S, Forssmann W-G and Frölich J C 2000 J. Chromatogr. B 74299

7. Peng H, Chen W, Cheng Y, Hakuna L, Strongin R and Wang B 2012 Sensors 1215907

8. (a) Shen J-S, Li D-H, Zhang M-B, Zhou J, Zhang H and Jiang Y-B 2011 Langmuir 27 481; (b) Pathak R K, Hinge V K, Mahesh K, Rai A, Panda D and Rao C P 2012 Anal. Chem. 84 6907; (c) Lo K K-W and Li S P-Y 2014 RSC Adv. 4 10560; (d) Xiong L, Zhao Q, Chen H, Wu Y, Dong Z, Zhou Z and Li F 2010 Inorg. Chem. 496402

9. (a) Qi L, Song J, Wu F-Y and Wan Y-Q 2014 Acta Chim. Slov. 61 73; (b) Li M-J, Zhan C-Q, Zheng Y-M, Chen G$\mathrm{N}$ and Chen X 2011 J. Nanosci. Nanotechnol. 11 3578; (c) Farhadi K, Forough M, Pourhossein A and Molaei R 2014 Sens. Actuators B: Chem. 202993

10. (a) Daniel M-C and Astruc D 2004 Chem. Rev. 104 293; (b) Ma D-L, Ma V P-Y, Chan D S-H, Leung K-H, He H-Z and Leung C-H 2012 Coord. Chem. Rev. 2563087 
11. (a) Siddiqui M M, Mobin S M, Senkovska I, Kaskel S and Balakrishna M S 2014 Chem. Commun. 50 12273; (b) Naik S, Kumaravel M, Mague J T and Balakrishna M S 2014 Dalton Trans. 43 1082; (c) Rashid A, Ananthnag G S, Naik S, Mague J T, Panda D and Balakrishna M S 2014 Dalton Trans. 43 11339; (d) Kumaravel M, Mague J T and Balakrishna M S 2014 Tetrahedron. Lett. $\mathbf{5 5} 2957$

12. Fourmy K, Mallet-Ladeira S, Dechy-Cabaret $\mathrm{O}$ and Gouygou M 2013 Organometallics 321571

13. Su H-C, Fadhel O, Yang C-J, Cho T-Y, Fave C, Hissler M, Wu C-C and Réau R 2006 J. Am. Chem. Soc. 128 983
14. He X and Yam V W-W 2011 Coord. Chem. Rev. 255 2111

15. Langdon-Jones E E and Pope S J A 2014 Chem. Commun. 5010343

16. Karver M R, Krishnamurthy D, Kulkarni R A, Bottini N and Barrios A M 2009 J. Med. Chem. 526912

17. (a) Tiekink E R T and Kang J-G 2009 Coord. Chem. Rev. 253 1627; (b) Koshevoy I O, Smirnova E S, Haukka M, Laguna A, Chueca J C, Pakkanen T A, Tunik S P, Ospino I and Crespo O 2011 Dalton Trans. 40 7412; (c) Ahmed L S, Clegg W, Davies D A, Dilworth J R, Elsegood M R J, Griffiths D V, Horsburgh L, Miller J R and Wheatley N 1999 Polyhedron 18593 